\title{
The Microscopy Society of America: Continuing to Grow and Excel
}

\author{
Robert (Bob) Price, MSA President
}

bob.price@uscmed.sc.edu

It is truly an exciting time for the Microscopy Society of America (MSA). As stated in the MSA mission statement, our society is "dedicated to the promotion and advancement of techniques and applications of microscopy and microanalysis in all relevant scientific disciplines." The MSA and its members have excelled in accomplishing this mission, and the financial success of the Society now allows funding of new initiatives to further accomplish the MSA mission and vision (www. microscopy.org/about/mission.cfm). Below I briefly detail some success stories related to existing efforts and provide information on new MSA initiatives.

The most visible MSA promotion of microscopy and microanalysis is certainly our Microscopy \& Microanalysis (M\&M) meeting, and M\&M 2018 in Baltimore was no exception. Led by Program Chair Yoosuf Picard and our meeting staff, including Nicole Guy (Meeting Manager) and Doreen Bonnema (Exhibits Manager), M\&M 2018 was our second largest meeting. An important component of any M\&M meeting is participation by students and young career professionals. The MSA and the Microbeam Analysis Society provided funding for 55 young microscopists to present their work at M\&M 2018. Our meeting continues to grow, and in 2019 we meet in Portland, Oregon, the site of the largest M\&M meeting in 2015. Based on reports from M\&M 2019 Program Chair Alice Dohnalkova, we can expect an even larger meeting than we had in 2015, especially considering the plenary lectures from Nobel Laureates Richard Henderson and Joachim Frank.

MSA publications are also important components in promoting and advancing our mission. Microscopy and Microanalysis (MaM), the peer-reviewed journal of the MSA led by Editor-in-Chief John Mansfield, publishes original research and review articles in microscopy, imaging, and compositional analysis. For the past three years MaM has also published a section titled "Micrographia" designed for publication of descriptive microscopy studies that are difficult to publish in journals that require bench-based research. Based on impact factor and number of pages published, MaM has been a leading microscopy journal for several consecutive years. Microscopy Today (MT), led by Editor-in-Chief Charles Lyman, is a trade magazine that covers a wide range of topics including new microscopy methods, industry news, tricks of the trade, and original articles in all areas of microscopy and microanalysis. Additional $M T$ functions include the Microscopy Today Innovation Awards and an exciting new international micrograph competition that will be held for the first time in 2019. Further information concerning the Micrograph Competition will be forthcoming. Along with our publishing partner, Cambridge University Press (CUP), we are also working out details to begin a new publication, Elements in Microscopy and Microanalysis. Elements will be a series of short ( 80 to 100 pages) online publications detailing advances in instrumentation and applications of microscopy and microanalysis. Our Editors, along with our CUP Publisher Aaron Johnson, have led the effort to make MSA publications worldwide brands with 13 affiliated microscopy societies, 7,257 worldwide library subscriptions, and more than 350,000 annual downloads of articles from $M a M$ and $M T$.

A major goal of Past President Ian Anderson was to increase student participation in MSA. The success of his efforts was recognized when our Student Council (StC) celebrated their first anniversary at M\&M 2018. The students also hosted their second pre-meeting congress, attended by over 70 young microscopists, where several students presented their research. The success of the congress promises to further increase the participation of student microscopists in MSA. The third student pre-meeting congress will be held at M\&M 2019. Although a relatively new MSA group, student leaders Jim Kilcrease, Josh Silverstein, Janet Gbur, Cameron Varano, Ethan Lawrence, Jae Yang, Will Bowman, and others have initiated several new projects and introduced new vigor into MSA as only young scientists can. Two key student-led efforts are the designation of student liaisons for all MSA Local Affiliate Societies and an effort by Josh Silverstein to create MOSAIC, a library of micrographs that will be prominently displayed on the MSA home page.

Under the direction of MSA Treasurer Peter Crozier, the financial security of MSA has never been better. With our long-term "Strategic Reserve" account now fully funded, the Society is able to use annual surpluses in new ways. Thus, MSA Council asked Jay Jerome to chair a committee to develop the MSA Strategic Initiatives Program. This effort will fund proposals to increase and disseminate knowledge in the science and practice of microscopy, with a strong emphasis on creation of new education and outreach programs that further the goals of MSA. The initial call for proposals, up to $\$ 15,000$ each, was published in the October issue of the members newsletter, MSA Update, with funding beginning in early 2019.

These examples represent a partial summary of MSA Council activity in 2018 and illustrate some of the success MSA has experienced in fulfilling its mission. None of this would have been possible without the leadership of previous MSA Councils in creating a strong annual meeting, a competitive publications portfolio, and an effective organization for association management. Special recognition is due to our Association Management team of Bob Dziuban (retired), Steven Jones, and Ashley Carey who help in all aspects of MSA management.

To all MSA members and other microscopists who have contributed to our meetings, publications, society outreach, and many other activities, I give my sincere thanks. It has been an honor to serve in various MSA roles since 1986 and as MSA President in 2018. I look forward to the further success of MSA under the leadership of our next President, Paul Kotula. 


\section{VICimoscony \\ Innovation Awards}
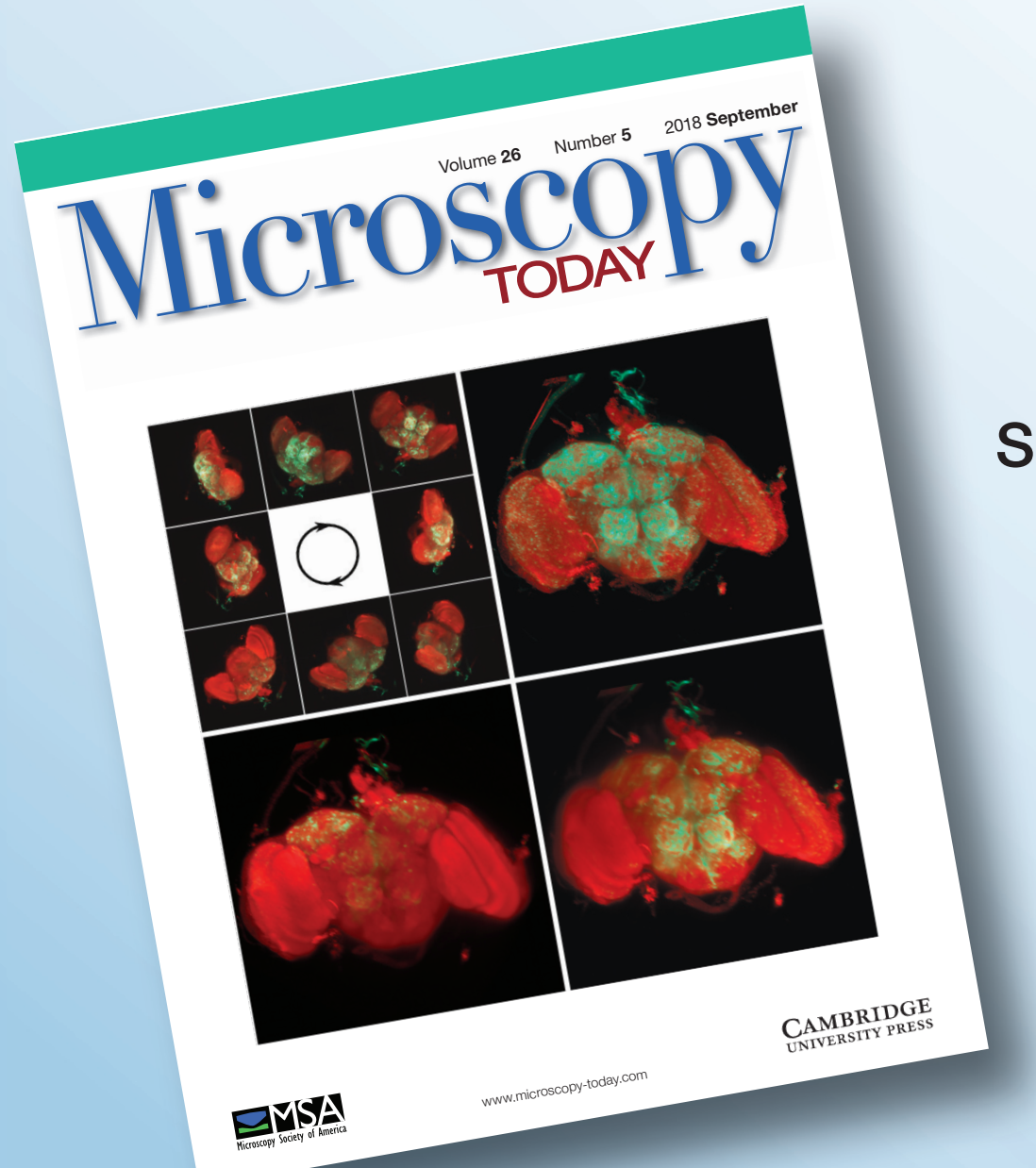

See the September 2018 issue for details about this year's winners

Request application forms by email:

charles.lyman@lehigh.edu

Next deadline - March 21, 2019 